\title{
DINÂMICA DO USO E OCUPAÇÃO DO SOLO NA PEQUENA CIDADE DE TERRA BOA (PR), BRASIL
}

Paulo Sergio Gusmão ${ }^{1}$ Marcos Clair Bovo²

Resumo: O uso e a ocupação do solo urbano estão ligados ao processo de produção capitalista e ao modo de ocupação de determinado lugar da cidade. Esses lugares concentram atividades industriais, comerciais e residenciais, além de instituições públicas. Assim, o uso e a ocupação do solo devem ser definidos de acordo com as atividades e equipamentos distribuídos no espaço urbano, sendo que as funções podem variar no tempo e no espaço. Diante disso, o artigo objetiva analisar a dinâmica do uso e ocupação do solo na área central da pequena cidade de Terra Boa (PR). O aporte metodológico foi constituído de pesquisa bibliográfica, documentos oficiais do município, pesquisa in loco e elaboração de produtos cartográficos a partir do Corel Draw. Os resultados possibilitaram identificar os diferentes usos e ocupação da área central da cidade de Terra Boa, sendo estes ligados aos setores comerciais, alimentícios, serviços e de áreas residenciais.

Palavras-chave: Solo urbano. Ocupação. Funcionalidade. Centro.

\section{DYNAMICS OF USAGE AND OCCUPATION OF SOIL IN THE SMALL TOWN OF TERRA BOA (PR), BRAZIL}

Abstract: The usage and occupation of urban soil is linked to the process of capitalist production and to how certain places in the city are occupied. These places gather industrial, trade and residential activities, besides public institutions. Thus, the usage and occupation of soil must be defined according to the activities and equipment delivered in the urban space, varying in time and space. In face of that, this article aims at analyzing the dynamics of usage and occupation of soil in the central area of the small town of Terra Boa (PR). Methodological support is given by bibliographical research, official documents from the municipality and on-site research, and Corel Draw graphics. Results allowed identifying different usages and occupation of the central area in Terra Boa, linked to commercial, food and services sectors, and to residential areas.

Keywords: Urban soil. Occupation. Functionality. Center.

\section{DINÁMICA DEL USO Y OCUPACIÓN DEL SUELO EN LA PEQUEÑA CIUDAD DE TERRA BOA (PR), BRASIL}

Resumen: El uso y ocupación del suelo urbano está vinculado al proceso de producción capitalista y al modo de ocupación de un lugar específico de la ciudad. Estos lugares concentran actividades industriales, comerciales y residenciales además de instituciones públicas. Así, el uso y ocupación del suelo deben ser definidos de acuerdo con las actividades y los equipos distribuidos en el espacio urbano, y las funciones pueden variar en el tiempo y el espacio. Por lo tanto, el

\footnotetext{
1Universidade Estadual do Paraná - UNESPAR, Campo Mourão, Brasil, e-mail: paulsergyogusmon@gmail.com, https://orcid.org/0000-0002-1961-1659

2 Universidade Estadual do Paraná - UNESPAR, Campo Mourão, Departamento Geografia, Campo Mourão, Brasil, e-mail: mcbovo69@gmail.com, https://orcid.org/0000-0003-3582-6702
} 
artículo tiene como objetivo analizar la dinámica del uso y ocupación del suelo en el área central de la pequeña ciudad de Terra Boa (PR). El enfoque metodológico consistió en la investigación bibliográfica, documentos oficiales municipales y la investigación in loco y elaboración de productos cartográficos utilizando Corel Draw. Los resultados permitieron identificar los diferentes usos y ocupación de la zona central de la ciudad de Terra Boa, que están vinculados a las áreas comerciales, de alimentos, servicios y residenciales.

Palabras clave: Suelo urbano. Ocupación. Funcionalidad. Centro.

\section{Introdução}

O centro urbano define-se como polo dinamizador dentro das cidades, estabelecendo-se como marca característica da urbe capitalista moderna e que reflete o cenário econômico e sua dinâmica interna. Ao mesmo tempo em que se pontua como um espaço de concentração das atividades econômicas ligadas ao comércio, serviços, instituições financeiras e governamentais, clínicas médicohospitalares. Em suma, uma gama de estruturas e equipamentos voltados para 0 atendimento do setor de negócios e da vida cotidiana urbana, ao mesmo tempo, que comporta para si os agentes decisórios da vida política urbana e que delineiam as ações e demandas da cidade.

Lócus do consumo, de decisões, de convívio, de trabalho, de trocas econômicas, sociais e culturais, o centro é o ponto de convergência dos fluxos e da circulação de pessoas que residem na cidade para satisfação das suas necessidades de consumo, trabalho e também confirmação dos seus interesses e reforço da identidade de coletividade entre os citadinos.

Além disso, o centro permite a comunicação e interlocução entre os atores sociais que produzem e reproduzem a urbe, garantindo-Ihe dinamicidade e o constante fluxo de bens materiais e imateriais que permitem a ampliação do potencial de desenvolvimento econômico do aglomerado urbano.

Assim, a pequena cidade de Terra Boa-PR, que foi colonizada em 1951, pela Companhia Melhoramentos Norte do Paraná, como outras aglomerações urbanas no norte paranaense, constitui objeto de estudo desta pesquisa. Segundo Ferreira (2006) foi por meio da Lei n. o 2.411, de 13 de julho de 1955, constituiu-se o município com território desmembrado de Engenheiro Beltrão e sua instalação oficial ocorreu em 11 de dezembro desse mesmo ano.

Conforme informações apresentadas no Caderno Estatístico do Município de Terra Boa, elaborado pelo IPARDES (2018), o município pertence ao Terceiro Planalto Paranaense ou Planalto de Guarapuava. Localizado na Mesorregião 
Centro-Ocidental Paranaense, na Microrregião Geográfica de Campo Mourão. A área territorial é de 325,656 $\mathrm{km}^{2}$.

De acordo com os dados do Instituto Brasileiro de Geografia e Estatística (IBGE, 2018), a população estimada para o município é de 16.984 habitantes (IBGE, 2018. E segundo o Atlas do Desenvolvimento Humano no Brasil (2013), o IDHM de Terra Boa é de 0,728, considerado alto conforme as diretrizes do programa.

Diante disso, o artigo objetiva analisar a dinâmica do uso e ocupação do solo na área central da pequena cidade de Terra Boa (PR).

\section{Reflexões sobre o uso e ocupação do solo}

As discussões ligadas ao conceito de cidade demonstram sua complexidade, ao mesmo tempo reforça que a mesma é compreendida a partir das funções e usos presentes nela. Dessa forma, autores como Carlos (1992), Côrrea (1999) e Souza (2005) definem-nas a partir de seu caráter funcional e pela justaposição de distintos usos e ocupações sobre si. Souza (2005), partindo desse pressuposto define como: "a cidade é, sob o ângulo do uso do solo, ou das atividades econômicas que a caracterizam, um espaço de produção não-agrícola [...] e de comércio e oferecimentos de serviços" (SOUZA, 2005, p. 27).

A compreensão da cidade a partir desse parâmetro "o uso do solo" permite averiguar a dinamicidade da urbe devido que esse fator está exposto às mudanças geradas pelas necessidades do capitalismo, que conforme Milton Santos (1985) "[...] são tantos espaciais como econômicas, culturais e políticas" que alteram "[...] a produção propriamente dita, a circulação, a distribuição e o consumo [...]" (SANTOS, 1985 , p. 47) que redefinem os tipos de uso presentes em cada parte da cidade, alterando o cenário produtivo e as funções urbanas. Tais modificações nos usos devem-se não somente pela conjuntura econômica, mas devido também às facilidades concedidas por cada lugar dentro do espaço urbano (SANTOS, 1985).

Dessa forma, reforçamos que a cidade, além de ser um produto social materializado pelo trabalho humano, materializa-se enquanto formas de ocupações (CARLOS, 1992), e este provém "da necessidade de realização de determinada ação, seja de produzir, consumir, habitar ou viver" (CARLOS, 1992, p. 45).

Portanto, para Carlos (1992), o uso do solo quando conectado ao processo de produção das relações capitalistas, caracteriza-se como forma de ocupação de 
determinado local da cidade, variando conforme o desenvolvimento das forças produtivas.

Nesse sentido, a autora destaca que a produção espacial se efetiva no cotidiano das pessoas e se materializa no modo de ocupação e/ou uso de determinado local, contudo o uso do solo urbano é marcado por conflitos entre usos e indivíduos e que tais conflitos são guiados pelo mercado (CARLOS, 1992).

Carlos (1992) destaca ainda que a forma como os tipos de uso do solo se estrutura dentro do tecido urbano se deve como as atividades são materializadas na cidade e são influenciadas pelos seguintes fatores:

No caso do lugar dedicado à atividade produtiva, a diminuição dos custos de produção será a coordenada principal a ser seguida; no caso da atividade comercial, o acesso ao mercado; no caso da circulação, as vias rápidas que tendem eliminar o processo de desvalorização do capital, diminuindo cada vez mais o tempo de percurso; no que se refere aos serviços, determinados tipos tenderão a localizar-se em áreas próximas aos centros de negócios, outros nas radiais, outros ainda em zonas específicas. Finalmente, o uso residencial será determinado pelo papel que cada indivíduo ocupará (direta ou indiretamente) no processo de produção geral da sociedade e, consequentemente, o seu lugar na distribuição da riqueza gerada (CARLOS, 1992, p. 46).

Dessa maneira, o processo de apropriação do capital pelos diferentes atores da sociedade determina como os usos serão distribuídos dentro do tecido urbano, definindo as localidades da implantação de comércios, serviços, indústrias e instituições públicas (como hospitais, escolas, órgãos institucionais, entre outros), como discutido por Carlos (1992).

Para Del Rio (1990), relaciona-se aos tipos de funções e intensidade no uso dos solos e edificações; buscando "uma variedade e mistura de funções compatíveis entre si e a mais intensa utilização possível 24 horas por dia, com densidades compatíveis, a fim de gerar uma área urbana com maior vitalidade possível [...]" (DEL RIO, 1990, p. 108).

Já Ferrari (1988) define o solo com a predominantemente atividade de seus equipamentos na área analisada, e que se classifica da seguinte forma: usos residenciais; usos industriais; usos comerciais; usos institucionais (públicos e privados); áreas de circulação e áreas vagas públicas ou privadas: próprias ou impróprias ao uso urbano) (GAROTTI, 2008).

Conforme Singer (1979), o uso do solo na economia capitalista é orientado por mecanismos de mercado que define o preço da mercadoria a partir do acesso e 
utilização do espaço, sendo que o acesso pode ser adquirido por compra do direito à propriedade ou pagamento de aluguel periodicamente.

Queiroz (2003) discute que o uso e a ocupação do solo estão ligados ao modo de povoamento do território. E refere-se "[...] à relação entre a área do lote e à quantidade de edificação que se coloca dentro dele e que tem o objetivo de realizar - equilíbrio da densidade urbana, que considera dois problemas: a densidade populacional e a densidade de edificação" (QUEIROZ, 2003, p. 27).

Segundo Queiroz (2003), existe dois parâmetros de análise do uso do solo urbano, o que destaca o equilíbrio da densidade urbana, garantindo o controle da ocupação dos terrenos urbanos com propósito de gerar uma distribuição equitativa e funcional da densidade, "tanto das edificações quanto das populações compatível com a infraestrutura e equipamentos de cada área considerada" e cada parâmetro refere-se "a primeira consiste na distribuição da população no solo urbano, relacionando habitante com área urbana. A segunda consiste na quantidade de edificação ( $\mathrm{m}^{2}$ de área construída) relacionada à área do terreno (taxa de ocupação)" (QUEIROZ, 2003, p. 27).

No entanto, Carlos (1992, p. 43) questiona as condições proposta por Queiroz (2003) ao afirmar que a organização do uso do solo urbano não se restringe somente ao modo de povoamento do território e sua relação com a densidade de exploração dos lotes, mas também se vincula "[...] ao processo de produção e reprodução do capital e [...] à reprodução da sociedade, tanto da força de trabalho [...] quanto da população em geral (consumidores). Tal diferenciação emergiu da noção de espaço-produto".

Assim sendo, a autora discute que devido as áreas do espaço urbano serem imprescindíveis para a atuação da lógica capitalista por fornecerem as condições primárias para o funcionamento das atividades econômicas estratégicas para a economia de mercado, essas se tornam mais valorizadas do ponto de vista econômica, minimizando o seu acesso a aqueles com maior poder aquisitivo (CARLOS, 1992).

Esses espaços com alto teor valorativo são conforme Castell (2009, p. 311), o centro urbano, devido ser a área de confluência do conteúdo social, das vias de comunicação, consolidando-se como um local geográfico, ao mesmo tempo como integrador e simbólico. Para tal, reforçamos neste artigo a compreensão de centro como "espaço que permite, além das características de sua ocupação, uma coordenação das atividades urbanas, uma identificação simbólica e ordenada destas 
atividades e, daí a criação das condições necessárias à comunicação entre os atores".

\section{Procedimentos metodológicos}

O município de Terra Boa (Figura 1) localiza-se na porção centro-ocidental do Estado do Paraná e integra a Mesorregião Centro-Ocidental Paranaense, pertencendo à Microrregião Geográfica de Campo Mourão. O município limita-se com os seguintes municípios: ao norte com Doutor Camargo, Ivatuba e Ourizona, a leste com Engenheiro Beltrão, ao sul com Araruna e Peabiru e a oeste com Jussara.

O aporte metodológico foi constituído de pesquisa bibliográfica em periódicos científicos, em livros, em teses e dissertações referentes ao uso e ocupação do solo. Também obtivemos dados estatísticos sobre o Município de Terra Boa por meio do Instituto Brasileiro de Geografia e Estatística, por intermédio da plataforma IBGE Cidades (<https://cidades.ibge.gov.br/>), e do Instituto Paranaense de Desenvolvimento Econômico e Social (IPARDES) (<http://www.ipardes.gov.br/>) e leis orgânicas relacionadas ao planejamento do espaço urbano, como Plano Diretor Municipal de Terra Boa (2008) e o Programa de Desenvolvimento Industrial e Econômico de Terra Boa - PRODETERRA (Leis municipais n. 985/2009; n. 1474/2017 e n. 1502/2018). E, por fim utilizamos o Google Earth com o objetivo de realizar o reconhecimento prévio das áreas para adquirir uma noção dos locais de pesquisa. 
Figura 1 - Localização do município e da sede urbana de Terra Boa (PR).

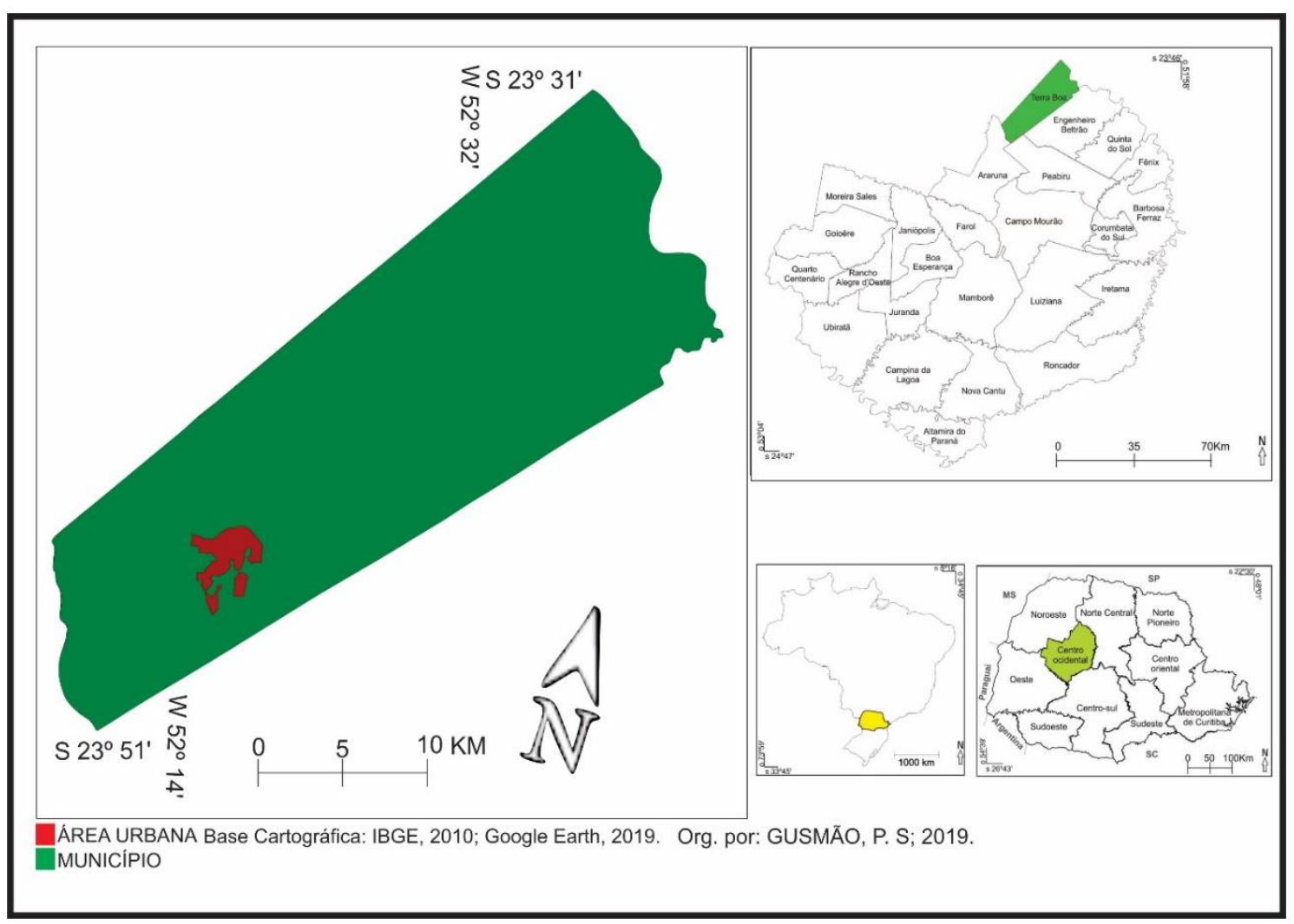

Fonte: IBGE, 2010; Google Earth, 2019. Org. GUSMÃO, P. S; 2019.

Outro aporte metodológico foi constituído de pesquisa in loco para observação e determinação dos diferentes tipos de uso do solo presentes nos locais delimitados. O processo de identificação dos tipos de uso do solo urbano presentes nas áreas estudadas foi pautado na metodologia desenvolvida por Bovo e Oliveira (2014), por meio de observação in loco, foi determinado o tipo de ocupação de cada lote, ou seja: em comércio, serviços, alimentação, residências, praças, hospitais, clínicas odontológicas, instituições religiosas, imóveis em reforma, construções, edifícios públicos e outros serviços.

Em seguida, as informações obtidas por meio dos dados estatísticos foram tabuladas em gráficos por meio do Excel ${ }^{\circledR}$ e os dados coletados em campo foram processados em produtos cartográficos a partir do Corel Draw®, gerando um mapa de localização do município e da sede urbana de Terra Boa e um mapa de uso e ocupação do solo da área central.

\section{Análises dos usos e ocupação do solo}

As atividades elencadas por Castell (2009) e por Corrêa (1999) encontram-se presentes no centro urbano terrabonense, sendo estas: as atividades comerciais, 
como lojas de vestuários, calçados, supermercados, farmácias, e comércios em geral; os serviços, como tornearias, automecânicos, autopeças, bancos, imobiliárias; de gestão pública e privada, como prefeitura, câmara municipal, fórum judicial; e os terminais de transportes interurbanos e inter-regionais, que no caso da área estudada restringe-se ao um terminal rodoviário, além de que a cidade de Terra Boa não possui processo de verticalização, elemento comumente presente em áreas centrais de médias e grandes cidades.

Dessa forma, reiteramos que o centro urbano de uma cidade é reflexo de sua dinâmica, sendo que a área central se coloca como detentora dos principais comércios e serviços especializados e também das instituições públicas e de gestão. $E$ no caso das pequenas cidades, como a do caso estudado, é na área central que se localiza a principal instituição religiosa, sendo em Terra Boa, a Igreja Matriz São Judas Tadeu.

De acordo com a pesquisa desenvolvida por Bovo e Oliveira (2014), a área central de Peabiru (PR) é semelhante à da cidade de Terra Boa que detém as principais relações econômicas e centraliza em si a maioria das atividades e serviços, concentrando também a sede do poder político municipal.

Nesse sentido, observamos que o centro da cidade, foco da pesquisa, apresenta uma dinâmica mais acentuada do que a área central da cidade de Peabiru (PR), estudada por Bovo e Oliveira (2014). Essa maior dinamicidade deve-se pelo crescimento econômico apresentado na década de 1980 e início da década de 1990 pela cidade; crescimento pautado na inserção da mesma no cenário da confecção e da moda, ligado ao eixo Maringá-Cianorte-Umuarama e que "coincide com o desenvolvimento desse setor na cidade de Cianorte-PR", conforme evidenciam os autores Beneton e Bovo (2009, p. 15).

O centro da cidade de Terra Boa define-se ainda como um espaço que congrega em si as características, "de produção, circulação e consumo; de trabalho para alguns, de moradias para outros, de lazer para muitos; e onde ocorre a socialização entre diferentes indivíduos" (THOMAZ, 2006, p. 56). O autor destaca que os diferentes usos da área central evidenciam por meio das práticas sociais, que se efetivam e se expressam materialmente, mudanças nas funções e na centralidade da cidade (THOMAZ, 2006), delineando novas possibilidades de atendimento da população local por novas especializações do centro urbano, como educacional, por implantação de redes de universidades privadas, que no caso da área estudada são representadas nas unidades de instituições privadas da Uningá e 
Unicesumar (educação a distância); como financeiro, pela presença da rede bancária (Banco do Brasil, Itaú e Bradesco) e pelas cooperativas de crédito, como o Sicredi e Sicoob; e decisional, como discute Lefebvre (2001), por conter órgãos institucionais que intervém no funcionamento da urbe por meio da tomada das decisões, no caso da cidade de Terra Boa é decidido pelo poder público, representado pela prefeitura e câmara municipal; pelos sindicatos diversos e a associação comercial e industrial (Asciterra); e pelo fórum de justiça.

A área central de Terra Boa possui uma relação estreita com a zona rural, como elencado por Bovo e Oliveira (2014) sobre a cidade de Peabiru (PR) devido à população rural, junto com a população urbana serem constituídas por consumidores dos bens e serviços oferecidos pelo centro urbano, devido se deslocarem semanalmente para a sede urbana, além de que o fortalecimento do setor comercial e de serviços dependem não somente das riquezas geradas pelo setor industrial, particularmente a confecção, mas também dos ganhos agrícolas que são injetados na economia urbana ampliando a demanda do mercado interno.

Outro fator que amplia a relação entre campo e a área central de Terra Boa e não visualizada nas discussões sobre o centro de Peabiru por Bovo e Oliveira (2014), deve-se a presença de estruturas criadas para beneficiar a produção e os investimentos no setor agrícola, que se estendem desde as políticas de incentivos agrícolas por parte do poder público, como atuação das cooperativas de créditos, rede bancárias e as cooperativas agrícolas (C. Vale e Cocamar), impulsionando a produção por meio da diversificação e acessos a financiamentos e renegociação de dívidas por parte dos agricultores, além de contar com apoio por meio da Emater e de empresas privadas especializadas nas vendas de diversos insumos para esse setor, sendo alguns exemplos a Moreli Agropecuária, Do Solo Agropecuária, Agrojar e a Fertiterra.

Contudo, a relação da área central de Terra Boa não se restringe somente às zonas urbana e rural da mesma, mas mantém pelas relações com os outros municípios do entorno, especialmente no que se refere às questões de saúde devido a moradores de outras cidades se deslocarem para a cidade em busca de atendimento médico especializado, especialmente geriatria e obstetrícia e para realização de exames médicos em clínicas particulares. Os outros segmentos que permitem a expansão da influência do centro para além das fronteiras municipal são: o industrial, particularmente, o têxtil, o alimentício e o de embalagens plásticas, cuja produção é exportada para outros polos nacionais e internacionais, além de ser 
reforçada pelo fato de possuírem filiais de outras regiões ou polos industriais tanto do Estado do Paraná quanto de outras unidades federativas "demonstrando assim uma interdependência com outras regiões industriais e comerciais de outros Estados" (BENETON; BOVO, 2009, p. 17).

Nesse sentido, a área central de Terra Boa revela-se um espaço resultante do acúmulo das relações sociais e econômicas, bem como sua temporalidade que expressa uma centralidade de escala intra e interurbana e possui uma maior variedade de atividades funcionais e perfis sociais, por concentrar as principais atividades e serviços da cidade (ARANHA SILVA, 2007), reforçando a existência de um centro que se consolida nas imediações da Avenida Brasil e que passou por um intenso processo de transformações sociais e econômicas e que moldaram esse espaço para um cenário novo e voltado para a lógica capitalista.

O outro fator que consolidada esse local como centro, a partir de Milton Santos (1959, p. 18), e ao mesmo tempo, como ponto central do núcleo urbano, "a capacidade de oferecer serviços e produtos à área que preside (básicos), enquanto as não-básicas apenas os ofereceriam aos moradores desse núcleo". O autor ainda explica que "os básicos são os que servem a mercados fora da cidade; e os nãobásicos aqueles cujo mercado é a própria cidade".

Nesse aspecto, o autor permite também enfatizar a consolidação do centro urbano terrabonense porque o mesmo não somente prioriza o fornecimento de serviços e produtos para o consumo interno da população local, mas também possui empreendimentos voltados para 0 atendimento dos mercados nacional e internacional, os quais priorizam o setor têxtil, o da moda, o calçadista e o de embalagens plásticas, sendo alguns dos mercados externos atendidos por produtos terrabonense, conforme Beneton e Bovo (2009; 2011), são os Estados Unidos (embalagens plásticas), Espanha e a Itália (confecção).

Por conseguinte, definimos como centro de Terra Boa, a área delimitada na Figura 2 que abrange as quadras adjacentes à principal via municipal, a Avenida Brasil, sendo que a maioria das atividades concentram-se no entorno dessa via, a qual é de fundamental importância para auxiliar na interligação da área central com os bairros periféricos, inclusive com a zona rural e com o distrito de Malu, por apresentar diferentes atividades econômicas diversificadas e especializadas, com a capacidade de atender uma gama distinta de público com diferentes perfis socioeconômicos. 
Destarte, mesmo com a concentração de atividades econômicas na espacialidade formada pela Avenida Brasil e suas ruas adjacentes, averiguamos também processos semelhantes ao visualizados por Ajonas (2009) em Itu (SP), que se definem com a expansão dessas atividades para outros setores do espaço urbano redesenhando o tecido urbano ao inserir novas áreas no cenário econômico urbano. Esse processo vem se consolidando em bairros como Jardim Fanny Lenner e no Jardim Bela Vista I e II que têm apresentado o desenvolvimento de comércios e serviços ligados ao circuito inferior, que conforme Milton Santos (2004): por essas atividades estarem voltadas à subsistência do agente e sua família, o processo de venda ocorre diretamente em contato com o cliente, sendo o uso da publicidade menor, normalmente por meio de anúncio em carros de som.

Portanto, ao mesmo tempo em que o centro agrega os fluxos e as atividades econômicas, apesar de estar se expandindo para outros pontos da cidade, observamos as marcas das transformações socioespaciais por meio da sua redefinição que anteriormente voltava-se à comercialização de produtos básicos, citados por Bovo e Oliveira (2014, p. 116), como as antigas lojas de secos e molhados, as boticas, entre outras que foram substituídas por modernas redes de supermercados, lojas de eletroeletrônicos, de vestuários e de calçados. E inserindo a cidade na lógica capitalista do sistema quaternário, destacamos recentemente o aparecimento de empresas especializadas no setor de informática e internet que permitiu à integração da urbe à dinâmica econômica e informacional global ao facilitar os fluxos de mercadorias, informações e das finanças.

Apesar da dispersão de atividades econômicas para outros setores do tecido urbano, constatamos a presença de único centro devido à maioria dos fluxos de pessoas e carros se deslocarem para a região da Avenida Brasil e as ruas circundantes, principalmente por motivos de consumo, de trabalho, de saúde, entre outros. Além de que as principais atividades culturais são restritas à área central, como feiras de exposição, de artesanato, de livros, atividades culturais, como o dia do desafio, e entrega de bens e veículos por parte do poder público e festividades de ano novo ocorrem nessa avenida, tornando-se outro fator para o deslocamento da população local para apreciação dessas atividades e festividades, garantido para si espaço de socialização e integração da comunidade local ao reforçar a identidade dos moradores com a cidade.

Devido às dinâmicas retratadas anteriormente, o centro possui um uso do solo diverso, principalmente de empreendimentos comerciais e prestadores de 
serviços, que conforme Milani e Silva (2009) são fundamentais para a atração dos consumidores, como retratado no estudo realizado pelos autores na cidade de Três Lagoas (MS).

Os estudos de outros autores também reforçam a centralização da Avenida Brasil e de suas ruas adjacentes, ao constatarem nas cidades por eles estudadas a intensa presença de usos residencial, comercial (varejista e atacadista) e serviços diversificados (bancos, escritórios, órgãos públicos) e rede clínico-laboratorial e hospitalar na área central, confirmado por estudos em Três Lagoas (MS) por Milani e Silva (2009); em Araguaína (TO) por Sodré (2017), em Peabiru por Bovo e Oliveira (2014) que permitiram detectar que nesses pequenos e médios centros urbanos suas atividades econômicas mais proeminentes se concentram na área central, particularmente nas principais avenidas e ruas de seu entorno, e alguns casos devese por ser o logradouro inicial dessas cidades.

Por conseguinte, pelas características destacadas anteriormente presentes no centro urbano, podemos repensar o próprio papel da cidade de Terra Boa dentro da rede urbana, demonstrando que suas características ultrapassam as condições de um centro local e posicionando-a no cenário urbano paranaense como um centro de zona.

No que tange à distribuição em percentual das atividades do centro, (Gráfico $1)$, destacamos que os principais usos são residenciais $(51,96 \%)$, comércio $(12,71 \%)$, serviços $(11,78 \%)$, datas vazias e imóveis fechados $(7,66 \%)$, alimentação (4,68\%), edifícios públicos $(4,30 \%)$, hospitais, laboratórios e clínicas diversas $(3,37 \%)$ e indústrias e fábricas $(2,24 \%)$. 
Gráfico 1- Tipos de usos e ocupações do solo urbano na área central da cidade de Terra Boa-PR.

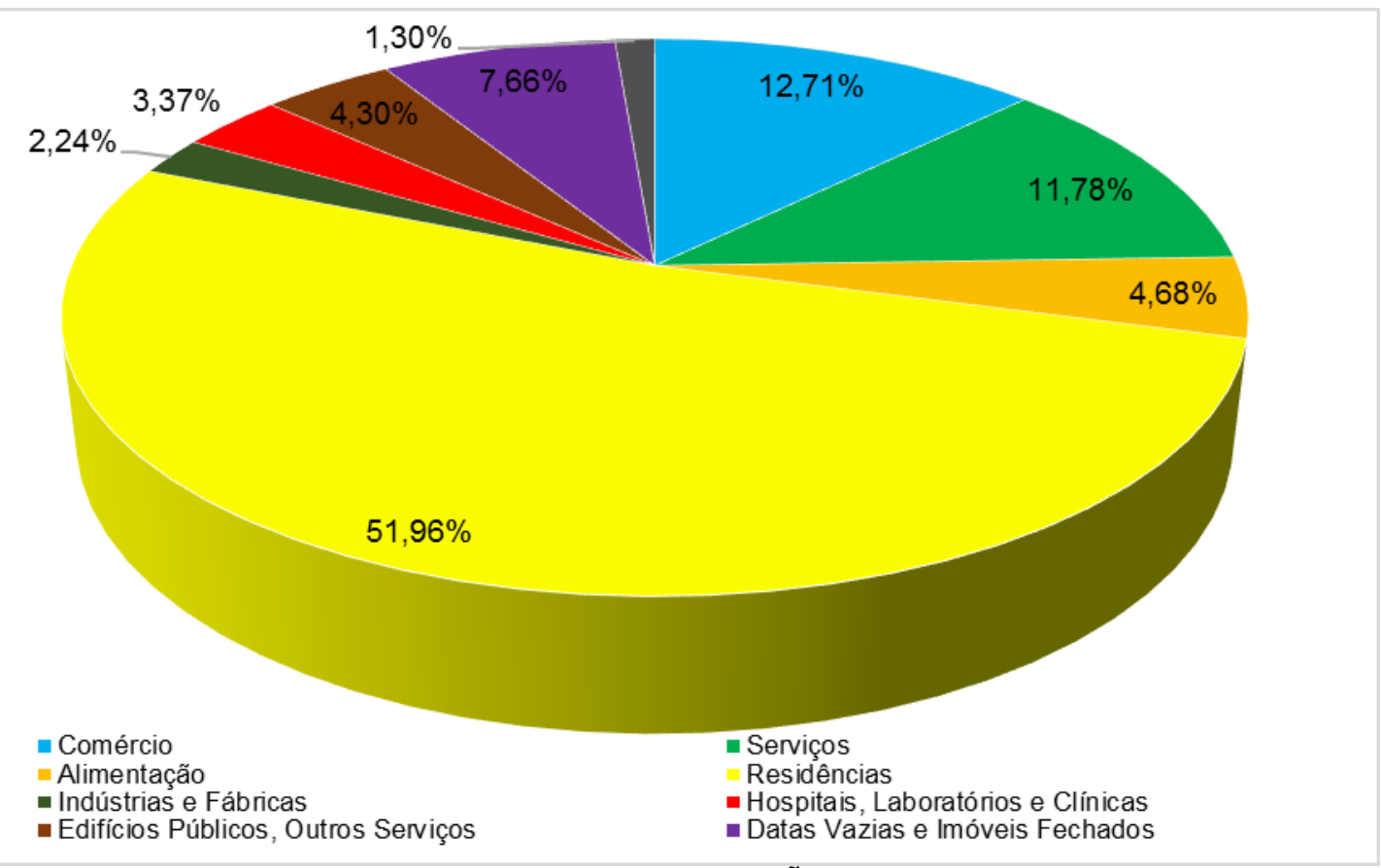

Fonte: Pesquisa de campo, junho de 2018. Org. por: GUSMÃO, P. S; 2019.

A distribuição das atividades presentes na área central, expressada no Gráfico 1, demonstram a capacidade do centro urbano de comportar os principais empreendimentos econômicos ligados aos diferentes setores comerciais, alimentícios e de serviços não somente pela concentração de moradores e de residências nessa porção da cidade, mas por ser o ponto de convergência de pessoas que se dirigem para o consumo, trabalho e o lazer.

No tocante à quantidade de tipos de usos presentes em cada um dos lotes da área central, constatamos que $88 \%$ apresentam apenas um tipo de ocupação, podendo ser somente residencial, comercial, serviços, entre outros, já dois tipos de usos por lotes somam 9,60\%, enquanto aqueles com mais de 3 tipos de usos do solo somam 2,35\%, conforme o Gráfico 2.

A concentração de apenas um tipo de uso limita a capacidade de diversificação das atividades econômicas dentro da área central, principalmente pela maioria dessas ocupações serem residências, tais condições impedem a ampliação dos tipos de empreendimentos em único lote. 
Gráfico 2: Quantidade de tipo de usos e ocupações do solo por lotes na área central da cidade de Terra Boa-PR.

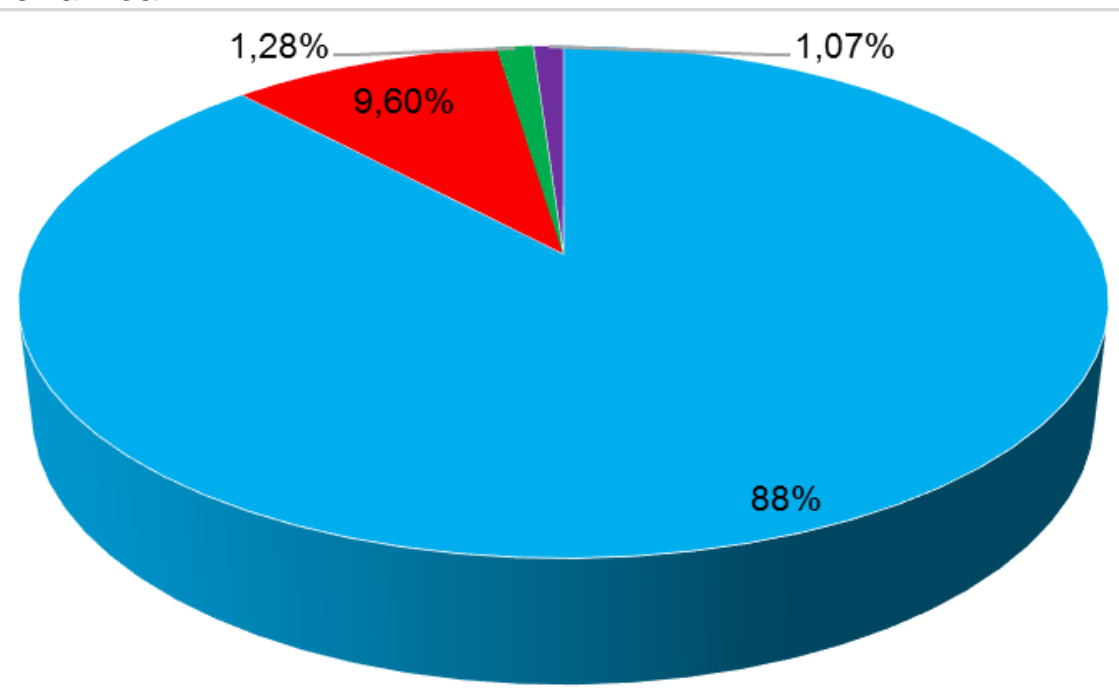

- Um tipo de uso - Dois tipos de uso =Três tipos de uso - Quatro ou mais tipos

Fonte: Pesquisa de campo, junho de 2018. Org. por: GUSMÃO, P. S; 2019.

Com relação ao uso residencial, destacam-se pelas condições de moradias e pelos padrões arquitetônicos, a concentração de segmentos da sociedade terrabonense com alto poder aquisitivo, principalmente empresários, profissionais liberais e funcionários do poder público e os ligados ao setor do agronegócio. Além de uma presença expressiva de residências em madeira resultante do período inicial da sede urbana.

Entretanto, destaca-se também, conforme o Gráfico 2 e figura 2, a presença de imóveis vazios, que se apropriam não somente do trabalho materializado alheio, como dos equipamentos e infraestruturas presentes na área central para gerar sobrevalorização, que seria a especulação imobiliária, fator que encarece os preços dos lotes urbanos no centro, impedindo que as populações menos abastadas consigam residir nessas áreas privilegiadas da cidade. 
Figura 02: Espacialização dos tipos de usos e ocupações do solo da área central.

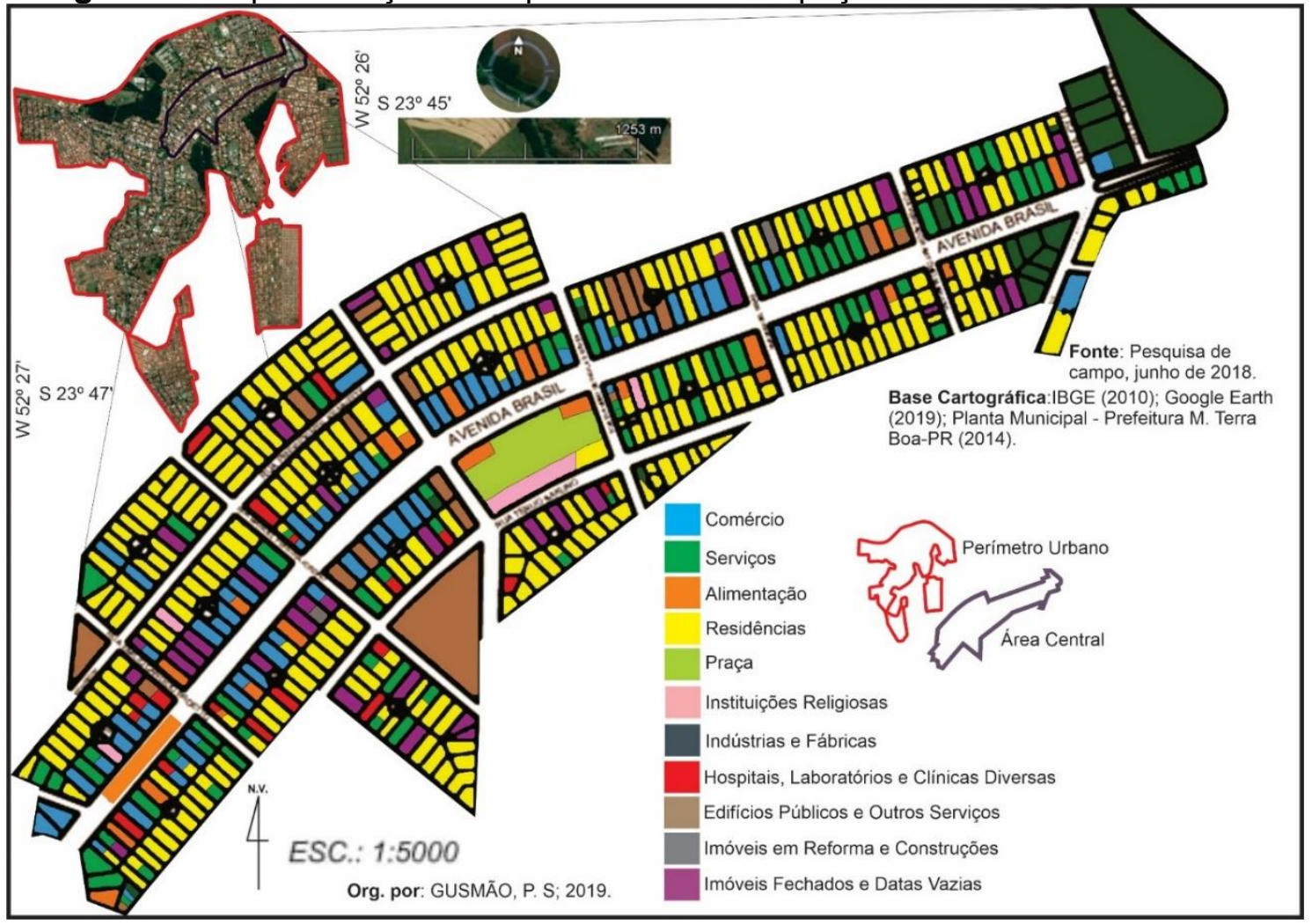

Fonte: Pesquisa de campo realizada pelo autor.

Com relação ao setor comercial, destacam-se os seguintes empreendimentos: vidraçaria, vestuário, móveis, mercados, sapataria, lojas de informática, revendedora de automóveis, lojas de perfumaria e cosméticos, distribuidoras de gás, casas agropecuárias, farmácias, papelarias, lojas de presentes e utilidades, lojas de materiais de construção, fotos, óticas, lojas de materiais elétricos, loja de tintas, relojoaria, entre outros.

Com relação ao setor de serviços, destacam-se os seguintes empreendimentos: borracharia, autoposto, salão de beleza, escritórios (diversos), oficinas mecânicas, tornearias, tapeçaria, escolas (línguas), bicicletaria, transportadoras, bancos e financeiras, chaveiro, lotérica, funerária.

Dentre os edifícios públicos e outros serviços sobressaem: Paço Municipal, Casa da Cultura, Sindicatos (diversos), Rádio, Cartório, Subestação de Telefonia OI, Colônia Japonesa, Associações (diversas).

Essas formas comerciais e de prestação de serviços descritos são para Lopes (2018), expressões da produção social do espaço "e explicam as constantes transformações no modo de consumir da sociedade", logo "essa produção, imbuída de conteúdo social, tem uma localização no espaço que lhe dá sentido e se reveste 
de significado social" (LOPES, 2018, p. 32). Complementando a autora, Carlos (2011) destaca que existe uma produção do espaço e uma produção de atividades no mesmo que legitimam uma localização diferencial das atividades humanas no espaço e carregam um significado material e simbólico.

Pintaudi (2013) pontua que os diferentes tipos de empreendimentos comerciais e sua distribuição com centro são resultantes das transformações sociais, especialmente do mundo da mercadoria e ao mesmo tempo, deve-se à capacidade de organização interna do espaço urbano que provém da competição entre as diferentes atividades econômicas para assegurar as localizações mais vantajosas por meio da superação das barreiras para a movimentação de pessoas, de mercadorias, e para o intercâmbio de bens, serviços e informações, conforme Camagni (2005).

Nesse sentido, o centro passaria a congregar as atividades comerciais e de prestação de serviços, como no caso da área estudada que apresenta uma maior especialização de produtos e serviços e necessita de um maior fluxo de informação para atrair clientes e fornecedores, dessa forma as empresas visando maximizar lucros passam a adotar as plataformas midiáticas, como sites próprios e mídias sociais (como Facebook, Instagram, Twitter, entre outros) e propagandas em emissoras de rádios para divulgar e cativar os consumidores.

Logo, esses segmentos econômicos se integram à lógica produtiva do circuito superior por apresentarem, de acordo com Milton Santos (2004), preços mais caros devido a qualidade do produto oferecido para uma demanda mais específica, apesar dos valores serem fixos, na qual "[...] o limite inferior não pode estar muito abaixo dos preços públicos do mercado, sob pena de colocar o futuro risco da firma" (SANTOS, 2004, p. 46). Além disso, reiteramos que essas empresas se baseiam na publicidade por permitir modificar os gostos e delinear o perfil da demanda, como exposto anteriormente.

Por conseguinte, reforçamos que a área delimitada na Figura 2 que compreende o entorno da Avenida Brasil, destaca-se como área central, conforme Corrêa (1999), por concentrar as principais atividades comerciais, de serviços, da gestão pública e privada. Além disso, concentra as principais atividades destacadas por Milton Santos (2004, grifo nosso) e congrega o que ele denomina de Circuito Superior da Economia Urbana, devido à área em estudo conter um comércio especializado, redes bancárias, órgãos públicos, serviços especializados que visem atender "um público mais exigente e preocupado com a qualidade dos produtos e 
serviços [...]" (BENETON; BOVO, 2011, p. 3). Além de apresentar o terminal rodoviário que conforme Corrêa (1999) é de suma importância para interligação e intercomunicação intra e interurbana. A figura 3 representa a igreja matriz no centro urbano terrabonense.

E por conter empreendimentos comerciais, serviços, estabelecimentos alimentícios e instituições públicas, o centro urbano apresenta uma ampliação da demanda de consumidores e de serviços e mercadorias no que se refere a outras localidades da cidade (BOVO; OLIVEIRA, 2014).

Quanto ao segmento de alimentação, o centro conta com lanchonetes, sorveterias, padarias, bares, restaurantes, pizzarias, açougue, estabelecimentos que comercializam frutas e verduras, possibilitando uma gama variada de alimentos. Além disso, conta com clínicas odontológicas, fisioterapêuticas, laboratórios de exames clínicos e hospitais. No tocante ao setor odontológico, a cidade possui atendimento especializado de boa qualidade, inclusive com capacidade cirúrgica, contudo as radiografias e a confecção de aparelhos odontológicos são realizadas em outras cidades. Com relação aos exames clínicos, o município possui estrutura para exames de raio-X (hospital municipal) e de ultrassonografia geral, doppler colorido, endocrinologia e biópsias são feitos em instituição privada (Clínica Ecoimagem), contudo exames de maior complexidade necessita do deslocamento dos pacientes para outros centros urbanos maiores.

Figura 3- Vista parcial do centro urbano da cidade de Terra Boa-PR.

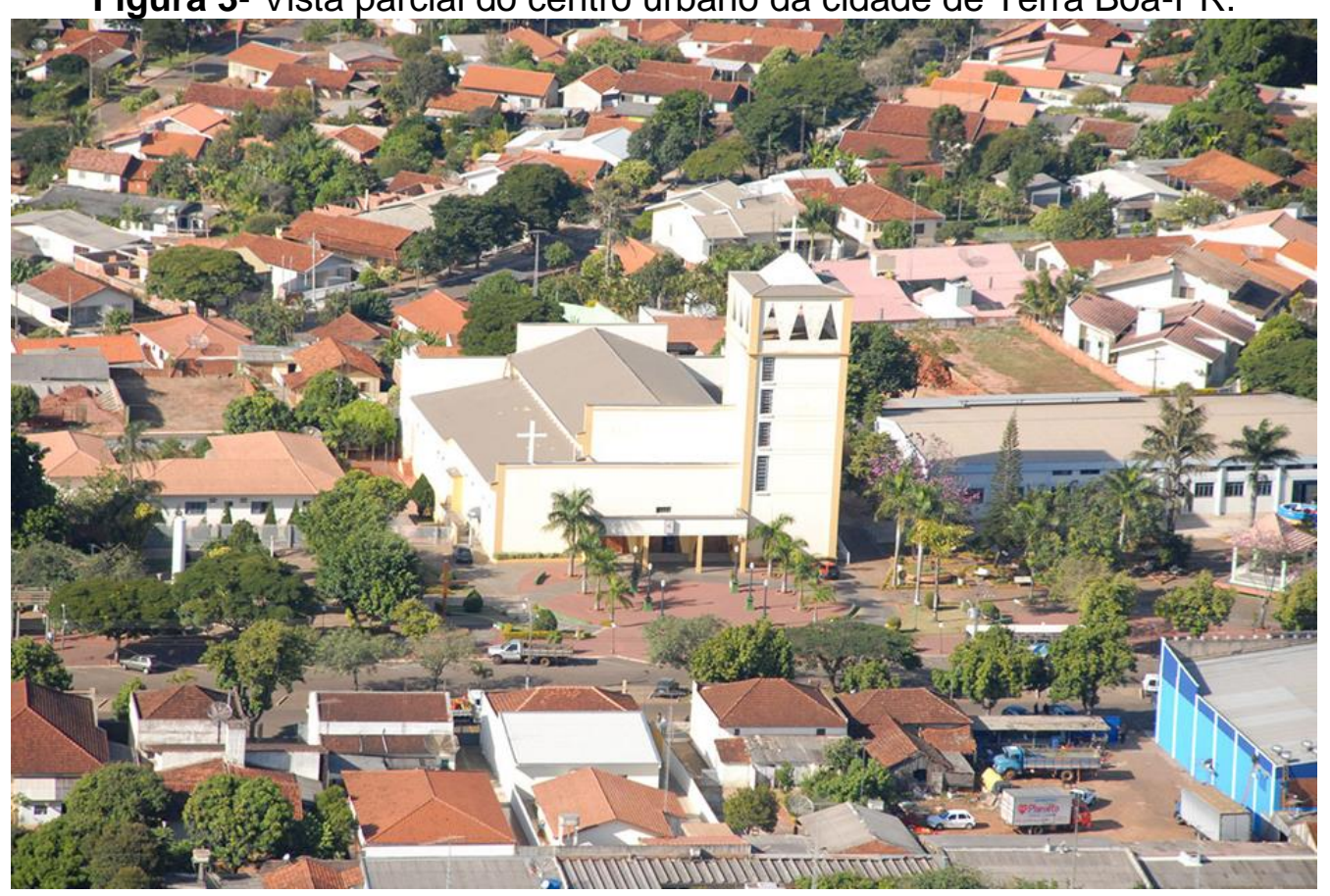

Fonte: Disponível em: https://www.viajeparana.com/Galeria-de-Imagens/Terra-Boa. Acesso 29 out. 2020. 
Esse segmento comporta em si uma fundamental importância do ponto de vista gastronômico ao permitir o contato e a degustação de pratos gastronômicos relacionados a diferentes culturas, ampliando as ofertas alimentares local, ao mesmo tempo em que proporcionam espaços de lazer, de descontração, de encontro e convívio entre amigos e familiares. Esses logradouros garantem para si o caráter de sociabilidade ao favorecer o diálogo e as trocas de ideias e informações entre as pessoas da comunidade local, aproximando interesses e debate pelo bem comum.

No setor industrial, conta com fábricas e facções de confecção, de calçados, de alimentos, de embalagens plásticas e de móveis planejados. A presença de pequenas e grandes unidades fabris na área central garante a geração de emprego e renda, além de propiciar a consolidação de espaço como de vital importância para o desenvolvimento urbano local.

Dentre as instituições religiosas, destaca-se a Igreja Matriz São Judas Tadeu, devido ao elevado número de moradores que frequentam esse templo religioso, conforme Gusmão e Bovo (2015).

Além disso, a área central de Terra Boa ao longo das últimas gestões públicas passou por diversos processos de renovação urbana, como aborda Ramires (1998) e Corrêa (1999) com alterações das características da infraestrutura para atendimento dos interesses econômicos e para facilitar o deslocamento de bens, mercadorias e pessoas, principalmente por meio de veículos motorizados, como motos, carros, ônibus e caminhões.

Esses processos de reforma visam criar infraestrutura que atendam os usuários de carros por meio da substituição dos canteiros centrais por estacionamentos para facilitar os deslocamentos de consumidores com conforto e comodidade, e conforme Gusmão e Bovo (2016), a Avenida Brasil conta com infraestrutura necessária para acesso da população nos estabelecimentos de serviços, nas lojas de comércio, nas instituições públicas, como também, com faixas de pedestres, rampas de acessibilidade, rampas de elevação (ou faixa elevada), semáforos, placas de sinalização, pontos de ônibus. Além de contar com um bom leito carroçável para deslocamento de veículos, contudo a mesma apresenta deficiências no tocante às suas calçadas, pois de acordo com os autores, os proprietários são responsáveis por sua construção manutenção. Assim, os 
proprietários acabam deixando-as de qualquer jeito ou as definem priorizando a saída de veículos do imóvel (VASCONCELLOS, 2012).

Dessa forma, constatamos que a partir dos dados coletados e da observação in loco, que a cidade de Terra Boa possui apenas um centro, que se define como:

[...] o espaço dotado de todas as qualidades do central, todos os atributos que definem o que é o centro da cidade; é resultante do acúmulo de tempos históricos, de lutas políticas [...] é possuidor de uma carga simbólica que está presente no imaginário da coletividade [...] do ponto de vista econômico, é a área que concentra a maior quantidade e diversidade de oferta de comércio e serviços e para onde convergem todos os meios de transporte coletivo que circulam os bairros (PEREIRA, 2014, p. 208).

Esse centro define-se não somente como detentor das atividades econômicas, retratadas por autores como Corrêa (1999), Johnson (1974), Machado (2013) e Santos (2004), mas como espaço de transformações socioespaciais resultantes das ações do poder públicos que pós-modernização agrícola introduziram no município a política de industrialização que gerou a modernização da infraestrutura econômica para atendimento da produção industrial e agrícola substituindo as antigas atividades comerciais pelas mais modernas. Nesse sentido, o centro atual é resultante dessas mudanças que o tornaram mais dinâmicos, segundo as exigências do mercado e do público consumidor. Mas, ao mesmo tempo, guarda para si o caráter simbólico e de identidade da comunidade local por ser o local inicial da sede urbana e pela presença da religiosidade marcada pela Igreja Matriz.

Logo o centro é o local do tecido urbano que concentra os equipamentos urbanos e congrega em si os fluxos de pessoas, bens, mercadorias e serviços que são marcados por diferentes usos do solo urbanos, os quais se mostram de forma fragmentada, mas que se articulam entre si por meio das relações sociais.

\section{Considerações finais}

As pesquisas sobre o uso e a ocupação do solo urbano em pequenas cidades são incipientes, tendo em vista que são realizadas com maior frequência em cidades de médio e grande porte. Foi diante dessa constatação que fomos tangidos a elaborar esta pesquisa com intuito de expor o funcionamento organizacional da pequena cidade de Terra Boa. 
Após concluir os estudos, verificamos que o centro da cidade de Terra Boa concentra diferentes atividades econômicas, serviços e fluxo diversos, pedestres, veículos, mercadorias, consumidores, além de ser uma área de acessibilidade e de infraestrutura urbana. É importante destacar também as relações sociais entre as pessoas (igrejas e praças e áreas de lazer), adquirindo, assim, características próprias de uma pequena cidade constituindo igualmente seu caráter de centralidade intra e interurbana, porém com menos intensidade que as cidades de porte médio e grande.

É relevante considerar que os pequenos municípios brasileiros com população inferior a 20 mil habitantes não têm obrigatoriedade de elaborarem o Plano Diretor que institui as diretrizes mínimas quando possível, para melhor ordenar o território municipal. Porém, Terra Boa possui legislação vigente sobre Uso e Ocupação do Solo e sobre Parcelamento do Solo, bem como com os princípios previstos no Plano Diretor Municipal, em conformidade com o $\S 1^{\circ}$ do art. 182 da Constituição Federal. Assim sendo, a lei de uso e ocupação do solo do município busca estabelecer os critérios para edificação dos lotes, tais como altura, coeficiente de aproveitamento; recuos, taxa de ocupação; taxa de permeabilidade; lote mínimo. Além dos planos setoriais existentes, como o plano de habitação.

Tais ações do poder público pressupõem organização e planejamento de forma que a área em estudo detém de equipamentos e infraestruturas, os quais contribuem para a sobrevalorização, ou seja, a especulação imobiliária, fator que eleva os preços dos lotes urbanos no centro, impedindo que as populações menos abastadas consigam residir nessas áreas da cidade.

\section{REFERÊNCIAS}

AJONAS, A. C. S. Centro e centralidade em Itu - SP. 2009. 171f. Dissertação (Mestrado em Geografia) - Universidade Estadual Paulista, Presidente Prudente, 2009.

ARANHA SILVA, E. A dinâmica socioespacial urbana e as novas centralidades em Três Lagoas. Três Lagoas, 2007.

BEAUJEU-GARNIER, J. Geografia urbana. Lisboa: Fundação Calouste Gulbenkian, 1980.

BENETON, J. C.; BOVO, M. C. Análise do setor industrial da cidade de Terra Boa/PR: projeção e interdependência econômica. In: Anais: I Simpósio de Estudos Urbanos: desenvolvimento regional e dinâmica ambiental, 2011, Campo Mourão. v. 1, p. 01-24.

BENETON, J. C.; BOVO, M. C. Análise prospectiva do setor industrial da cidade de Terra Boa/PR: um estudo de caso sobre a interdependência econômica entre os polos industriais. 
In: Simpósio O rural e o urbano no Brasil, 2. 2009, Rio de Janeiro. Anais... Rio de Janeiro: UERJ, 2009.

BOVO, M. C.; OLIVEIRA, M. A. Centro e centralidade urbana: uma análise da pequena cidade de Peabiru (PR), Brasil. Caderno Prudentino de Geografia, Presidente Prudente, n. 36, v. 2, p. 104-123, ago./dez. 2014. Disponível em:

<http://revista.fct.unesp.br/index.php/cpg/article/view/3061>. Acesso em: agosto. 2019.

CAMAGNI, R. Economía urbana. Universitat Autònoma de Barcelona, Barcelona, 2005.

CARLOS, A. F. A. A cidade. São Paulo: Contexto, 1992.

CARLOS, A. F. A. A condição espacial. São Paulo: Contexto, 2011.

CASTTEL, M. A questão urbana. São Paulo: Paz e Terra, 2009.

CORRÊA, R. L. O espaço urbano. São Paulo: Ática, 1999.

DEL RIO, V. Introdução ao desenho urbano no processo de planejamento. São Paulo: Pini, 1990.

FERRARI, C. Curso de planejamento municipal integrado: Urbanismo. São Paulo: Pioneira, 1988.

FERREIRA, J. C. V. Municípios paranaenses: origens e significados de seus nomes. Curitiba: Secretaria de Estado da Cultura, 2006.

GAROTTI, L. M. Caracterização urbanística e hidrológica do uso e ocupação do solo urbano da cidade de Ribeirão Preto - SP. 2008. 161f. Dissertação (Mestrado em Engenharia Urbana) - Universidade Federal de São Carlos, São Carlos, 2008.

GUSMÃO, P. S.; BOVO, M. C. Limites e possibilidades de uso do espaço público: uma análise da Praça João XXIII na cidade de Terra Boa (PR), Brasil. Anais... Encontro Anual de Iniciação Científica da Unespar, v. 1, 2015. Disponível em:

<http://www.fecilcam.br/eventos/index.php/eaic/EAIC/paper/viewFile/3069/969 2 . Acesso em: 27 maio 2019.

GUSMÃO, P. S.; BOVO, M. C. Mobilidade urbana: uso e ocupação do solo urbano na Avenida Brasil - Terra Boa-PR. In: Simpósio Nacional de Estudos Urbanos, 2016, Campo Mourão. Anais... Campo Mourão: Unespar, 2016.

LEFEBVRE, H. O direito à cidade. São Paulo: Centauro, 2001.

INSTITUTO BRASILEIRO DE GEOGRAFIA E ESTATÍSTICA. Agência IBGE Notícias.

Projeção da população 2018. Disponível em:

$<$ https://agenciadenoticias.ibge.gov.br/agencia-sala-de-imprensa/2013-agencia-denoticias/releases/21837-projecao-da-populacao-2018-numero-de-habitantes-do-pais-deveparar-de-crescer-em-2047>. Acesso em: 08 fev. 2019.

INSTITUTO BRASILEIRO DE GEOGRAFIA E ESTATÍSTICA. IBGE Cidades. Terra Boa. 2019. Disponível em: <https://cidades.ibge.gov.br/brasil/pr/terra-boa/panorama>. Acesso em: 08 fev. 2019. 
IPARDES. INSTITUTO PARANAENSE DE DESENVOLVIMENTO ECONÔMICO E SOCIAL. Cadernos municipais de Terra Boa. 2018. Disponível em: <http://www.ipardes.gov.br/>. Acesso em: 08 dez. 2018.

JOHNSON, J. H. Geografia urbana. Barcelona: Oikos-Tau, 1974.

LOPES, R. M. R. Dinâmica do comércio das áreas tradicionais no contexto do espaço urbano de Natal/RN. 2018. 267f. Tese (Doutorado em Geografia) - Universidade Federal do Rio Grande do Norte, Natal, 2018.

MACHADO, J. R. Processos e formas espaciais no espaço urbano: reflexões acerca dos conceitos centro, área central, centralidade e descentralização. In: BOVO, M. C.; TÖWS, R. L.; COSTA, F. R. (Orgs.). Estudos urbanos em perspectivas: reflexões, escalas e desafios. Campo Mourão: Editora da Fecilcam, 2013. 288p.

MILANI, P. H; SILVA, E. A. Centralidade urbana: um estudo do centro principal de Três Lagoas-MS. Geografia em atos, n. 9, v. 1, Unesp, Presidente Prudente, 2009. Disponível em: http://revista.fct.unesp.br/index.php/geografiaematos/article/view/265>.

Acesso em: 1 set. 2019.

PEREIRA, C. S. S. Centro, centralidade e cidade média: o papel do comércio e serviços na reestruturação da cidade de Juazeiro do Norte/CE. 2014. 329f. Dissertação (Mestrado em Geografia) - Universidade Estadual Paulista, Presidente Prudente, 2014.

PINTAUDI, S. M. A cidade e as formas de comércio. In: CARLOS, A. F. A. (Org.). Novos caminhos da geografia. 6. ed. São Paulo: Contexto, 2013. (Coleção Caminhos da geografia).

PREFEITURA MUNICIPAL DE TERRA BOA. Plano Diretor Municipal de Terra Boa. Terra Boa, 2008.

QUEIROZ, L. M. B. A evolução do uso e ocupação do solo urbano em Cacupé - Ilha de Santa Catarina. 2003. 130f. Dissertação (Mestrado em Engenharia de Produção) Universidade Federal de Santa Catarina, Florianópolis, 2003.

RAMIRES, J. C. L. A verticalidade e centralidade: o significado de morar na área central de Uberlândia. Boletim de Geografia. Rio Claro, v. 23, n. 2, 1998, p. 35-51.

SANTOS, M. A cidade como centro da região: definições e métodos de avaliação da centralidade. Salvador: Livraria Progresso Editora, 1959.

SANTOS, M. A Urbanização Brasileira. São Paulo: Hucitec, 1993.

SANTOS, M. Espaços e método. São Paulo: Nobel, 1985.

SANTOS, M. O Espaço Dividido: os dois circuitos da economia urbana dos Países Subdesenvolvidos. $2^{\underline{a}}$ ed. São Paulo: Editora da Universidade de São Paulo, 2004.

SINGER, P. O uso do solo na economia capitalista. São Paulo: Universidade de São Paulo - Faculdade de Arquitetura e Urbanismo, 1979.

SOUZA, M. L. ABC do desenvolvimento urbano. 2. ed. Rio de Janeiro: Bertrand Brasil, 2005. 
THOMAZ, F. Usos das vias urbanas em Presidente Prudente/SP: espaços públicos e legislação urbana. 240f. Dissertação (Mestrado em Geografia) - Universidade Estadual Paulista, Presidente Prudente, 2006.

VASCONCELLOS, E. A. Mobilidade urbana e cidadania. Rio de Janeiro: SENAC, 2012. VILLAÇA, F. Espaço intra-urbano no Brasil. São Paulo: Studio Nobel; FAPESP; Lincoln Institute, 2001.

\section{NOTAS DE AUTOR}

\section{CONTRIBUIÇÃO}

Paulo Sergio Gusmão: Redação e elaboração do manuscrito. Coleta e análise de dados. Participação e análise da discussão dos resultados. Revisão e aprovação da versão final do artigo.

Marcos Clair Bovo: Redação e elaboração do manuscrito. Coleta e análise de dados. Participação e análise da discussão dos resultados. Revisão e aprovação da versão final do artigo.

\section{FINANCIAMENTO}

Não se aplica.

\section{CONSENTIMENTO DE USO DE IMAGEM}

Não se aplica

APROVAÇÃO DE COMITÊ DE ÉTICA EM PESQUISA

Não se aplica

CONFLITO DE INTERESSES

Não se aplica

\section{LICENÇA DE USO}

Este artigo está licenciado sob a Licença Creative Commons CC-BY. Com essa licença você pode compartilhar, adaptar, criar para qualquer fim, desde que atribua a autoria da obra.

\section{HISTÓRICO}

Recebido em: 11-05-2020

Aprovado em: 26-08-2021 